\title{
X-Ray Microtomography Study to Validate the Efficacies of Caries Removal in Primary Molars by Hand Excavation and Chemo-Mechanical Technique
}

\author{
M. Ahmed G.R. Davis F.S.L. Wong \\ Centre for Oral Growth and Development, Institute of Dentistry, Barts \& The London School of Medicine and \\ Dentistry, Queen Mary University of London, London, UK
}

\section{Key Words}

Carisolv $\cdot$ Chemo-mechanical caries removal $\cdot$ Micro-CT .

Microtomography $\cdot$ Minimal intervention

\begin{abstract}
Background/Aims: Mechanical removal of carious dentine based on perceived hardness is subjective and tends to be excessively destructive; chemo-mechanical techniques have been proposed as being more objective and conservative. The aims of the present study are to use X-ray microtomography (XMT/micro-CT) to determine the three-dimensional mineral concentration distribution in sound, carious and excavated dentine using hand excavation (HE) and a chemomechanical, Carisolv (CS), removal technique for primary molars, and to compare the volume of sound dentine removed in order to validate the efficacies of these two techniques. Methods: Twenty-one primary molars with open carious cavities were hemisected. The carious tissue in one half was then removed by $\mathrm{HE}$ and the other by CS. XMT scans were taken before and after caries removal. After alignment, subtracted XMT images from the two scans revealing the tissues removed were generated, from which mineral distributions were determined, and volumes of sound dentine removed by each technique were calculated. Results: It was
\end{abstract}

found that the sound dentine removed by HE and CS techniques accounted for 4.0 and $2.1 \%$ of total tissues removed, respectively. The mean cut-off linear attenuation coefficients at $40 \mathrm{keV}$ to which HE and CS excavated to were 1.27 and $1.09 \mathrm{~cm}^{-1}$, respectively. The corresponding Knoop hardness number for the cut-off for CS was $25 \mathrm{~kg} \cdot \mathrm{mm}^{-2}$. Conclusion: It is concluded that using XMT, CS is validated to be more conservative than $\mathrm{HE}$ and preserves a layer of partially demineralised dentine with a mineral concentration $>0.97$ $\mathrm{g} \cdot \mathrm{cm}^{-3}$.

Copyright $\odot 2012$ S. Karger AG, Basel

Conventional teaching in caries management is largely based on G.V. Black's principles; one of which is 'extension for prevention', i.e. removing all trace of diseased tissues so that restoration can be placed on sound enamel and dentine to avoid secondary caries formation. This concept has been challenged in recent years and is now considered to be too invasive, compromising the pulp, and too destructive to the structural integrity of the tooth [Burke, 2003; Kidd, 2005]. However, the ideal extent of the 'diseased' tissue to be removed is still unclear.

Clinically, Black's idea of sound dentine is based on tactile hardness. When Fusayama et al. [1966] found that

\section{KARGER}

Fax +41613061234 E-Mail karger@karger.ch www.karger.com
(C) 2012 S. Karger AG, Basel

0008-6568/12/0466-0561\$38.00/0

Accessible online at:

www.karger.com/cre
Ferranti Wong

Paediatric Dentistry, Institute of Dentistry

Barts \& The London School of Medicine and Dentistry

Turner Street, London, E1 2AD (UK)

Tel. +44 207882 8745, E-Mail f.s.l.wong@ qmul.ac.uk 
carious dentine can be divided into 'infected' and 'affected' types, the main goal became to locate the boundary between these two types so that only the infected dentine is removed, leaving the affected dentine intact to be repaired by remineralisation. Since tactile hardness is operator dependant, thus subjective, chemical indicators have been used to differentiate the layers. These indicators include dyes which stain bacteria [Lula et al., 2009], and chemical gels that soften dentine containing denatured collagen for easy removal with a blunt instrument, a chemo-mechanical technique (e.g. Carisolv, CS) [Rafique et al., 2003; Clementino-Luedemann et al., 2006]. Air-abrasion, sono-abrasion, and polymer burs have also been suggested as techniques that would limit removal of excessive dentine [Banerjee et al., 2000; Boston, 2003].

Previous laboratory investigations on correlating carious indicators to mechanical properties of the dentine, or bacterial infiltration within the tubules, are usually confined to 2 dimensions (2D) [Banerjee et al., 2000; Angker et al., 2004; Fluckiger et al., 2005; Celiberti et al., 2006]. Furthermore, since most of the investigative techniques are destructive, it is difficult, if not impossible, to analyse the mineral distribution of the removed dentine, especially its spatial relationship in 3 dimensions (3D). In recent years, X-ray microtomography (XMT or micro$\mathrm{CT}$ ), is becoming a popular technique in dental research because of its non-destructive nature and ability to determine mineral concentration at micron level [Hahn et al., 2004; Clementino-Luedemann et al., 2006]. Willmott et al. [2007], using this technique, found that tissue removed by a steel bur in a rotary handpiece could contain up to $44 \%$ of sound dentine.

This present study aimed to use this novel XMT technique to validate and compare, in $3 \mathrm{D}$, the efficacies of two caries removal techniques, namely conventional hand excavation (HE) and the chemo-mechanical CS technique. Also, from the mineral distribution of the removed dentine, the level of dentine mineral concentration to which each technique excavated would be determined.

\section{Materials and Methods}

\section{Specimen Preparation}

Twenty-one extracted human primary molars with open carious cavities were obtained from patients with consent for this experiment (Research Ethics Committee Ref. No.: 06/Q0605/82). These teeth were stored in $70 \%$ ethanol. Each tooth was bisected longitudinally through the centre of an open cavity using a circular rotating saw (Microslice 2, Malvern, UK). The two halves were then reassembled together (with a $\sim 2$-mm gap) and mounted securely in a specially designed XMT stage. An aluminium wire ( $1 \mathrm{~mm}$ in diameter) was mounted along the gap for internal calibration. In order to prevent shrinkage through desiccation, drops of deionised water were placed on the sample which was wrapped tightly in cling film. The whole reassembled tooth was scanned (SCAN1) using a high definition XMT (MuCat) scanner at $30 \mu \mathrm{m}$ resolution, using a laboratory $\mathrm{X}$-ray source $(160 \mathrm{kV} \max , 5 \mu \mathrm{m}$ Ultrafocus, X-Tek, UK) with a tungsten target. This scanner had a time delay integration (TDI) configuration to avoid ring artefacts and to allow wide field imaging. Beam hardening effects were minimised by using a $1.2-\mathrm{mm} \mathrm{Al}$ and $50-\mu \mathrm{m} \mathrm{Cu}$ filter to reduce the X-ray spectral spread and by linearizing the projection data according to a 5 th-order polynomial curve derived from attenuation measurements of an aluminium step wedge. The linearized projection data approximated to that which would be obtained with a $40 \mathrm{keV}$ monochromatic source [Davis and Elliott, 2003]. A typical scan time for a tooth was approximately $6.5 \mathrm{~h}$ for 651 projections.

\section{Caries Removal and XMT Scan}

After SCAN1, the tooth specimen was taken to a clinician (F.S.L.W.), a consultant in paediatric dentistry with over 30 years of clinical experience, for caries removal in a clinical operatory environment. Each half of the tooth was randomly assigned by the flip of a coin to have caries removed by one of the following techniques: (1) HE - The clinician was instructed to excavate all the dentinal caries using a new spoon excavator (Excavator No.127/8 (Part No. 9790923); DE Healthcare Products, Gillingham, Kent, UK) following conventional method of judgement, i.e. until hard dentine was reached and further excavation did not remove any noticeable amount of dentine. (2) CS - The clinician was instructed to use the Carisolv (MediTeam/OraSolv, Sweden) system and follow the manufacturer's instruction to remove dentine caries. This procedure involved mixing the two components of the CS gel each time, applying the fresh mixture onto the lesion for $1 \mathrm{~min}$ and using the manufacturer's special hand instruments to 'scrape' away the softened tissue. The lesion was then washed and the procedure repeated until no noticeable amount of dentine could be removed.

The whole specimen then had a post-operative XMT scan (SCAN2) using the same parameters as SCAN1.

\section{Internal Calibration}

In order to correct for small spectrum shift between scans, the mean linear attenuation coefficient (LAC) of the Al wire that was scanned beside the specimen was measured. The LACs of the whole image were then standardised using the ratio of the published LAC for Al at $40 \mathrm{keV}$, which is $1.53 \mathrm{~cm}^{-1}$ [Hubbell and Seltzer, 1995], to the measured value.

\section{Visualisation and Analysis}

A number of in-house software programs and commercial packages including AMIRA 5.3.3 (Template Graphics Software Inc., USA), IDL 6.3 (ITT, USA) were used to first reconstruct the XMT data into a 3D format and subsequently analyse the volume image in order to calculate the amount of tissue removed by each method. An 'alignment and subtraction' software routine was used to align the images of the same specimen between the scans in order to produce a subtracted image from which the mineral 


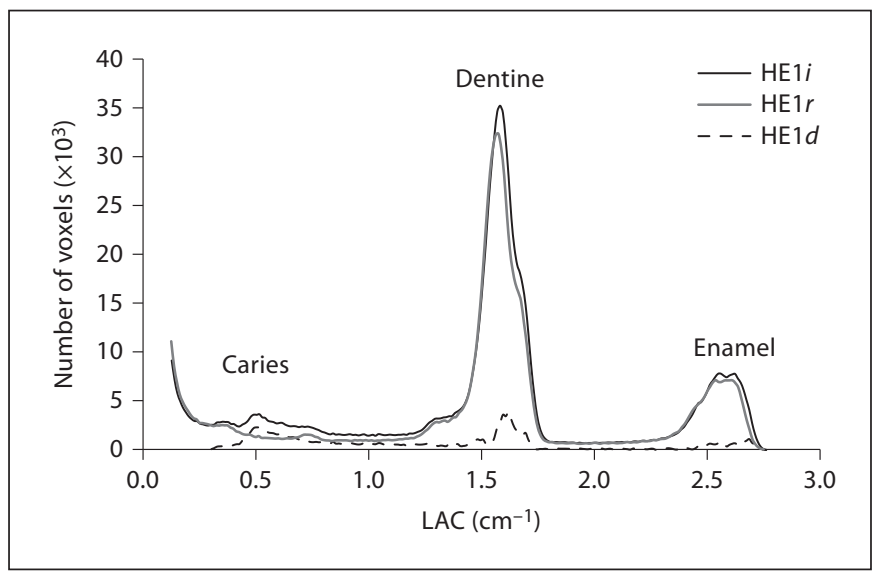

Fig. 1. Typical LAC histograms for a hemisected tooth before (HE1i) and after (HE1r) HE, and the difference histogram (HE1d).

distribution of the removed tissue was determined. From this distribution, the volume proportion of removed sound dentine to the total removed tissue was calculated. In order to visualise and measure the dentine mineral level to which each technique excavated to, 2D analysis was carried on a sagittal plane slice of the XMT image, close to the cut surface.

\section{Results}

\section{D Analysis}

Typical LAC histograms of a half tooth that had caries removed by $\mathrm{HE}$ (HE1) are shown in figure 1. The LAC ranges for sound enamel and dentine were 2.3-2.8 and 1.4$1.7 \mathrm{~cm}^{-1}$, respectively. Dentine that had a LAC below 1.4 $\mathrm{cm}^{-1}$ could be regarded as carious dentine. HE1 $i$ and HE1 $r$ are histograms from SCAN1, before caries removal, and from SCAN2, after caries removal, respectively. A third histogram was generated by subtracting the histogram of HE1 $r$ from HE1 $i$ to show the distribution of LACs of removed tissue (HE1d). The main features shown in HE1 $i$ and HE1r are the high enamel and dentine peaks, with a much lower and spread out caries peak in HE1i. In HE1d, it could be observed that not only carious dentine was removed, but also a noticeable amount of sound dentine.

Although the above simple histogram subtraction method gives a good overview, small specimen movement between the scans might cause a shift in the superimposition, and consequently, a spatial shift in the subtraction. Furthermore, it was discovered that the two hemisections could move independently to each other. In order to overcome this misalignment error, the tooth

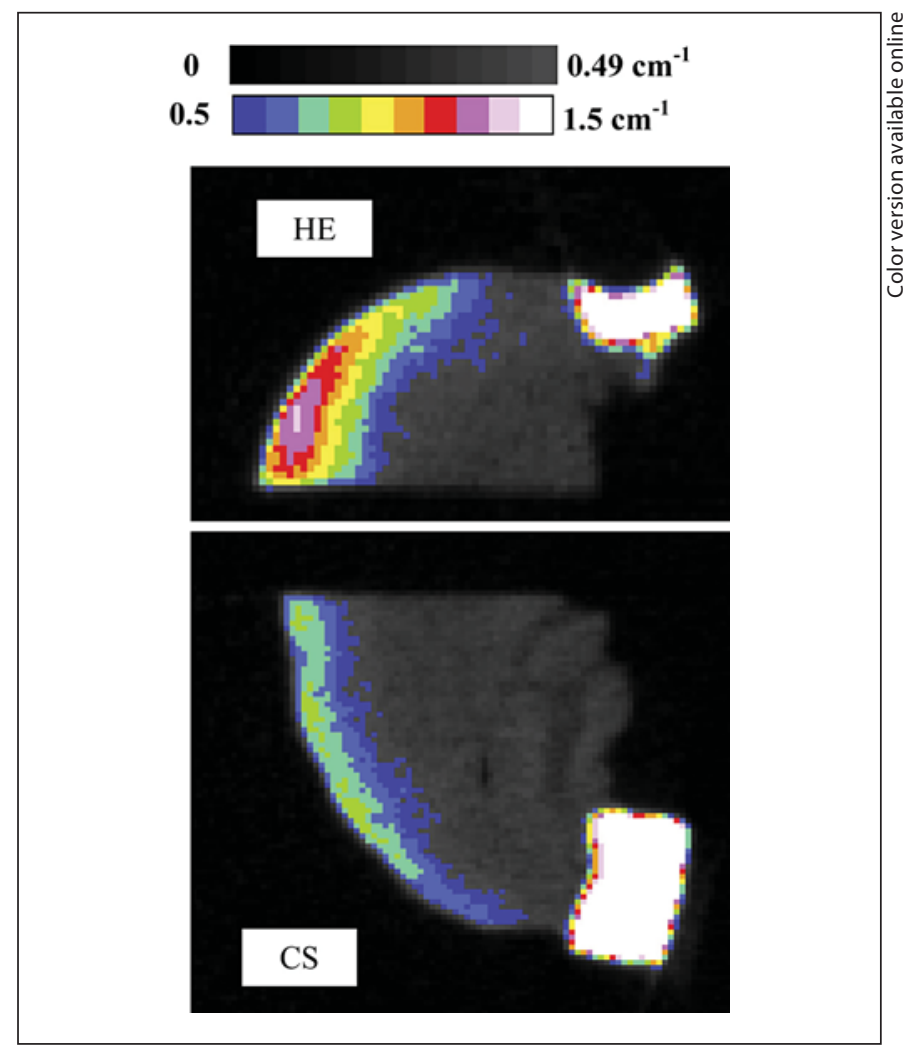

Fig. 2. XMT slice with LAC pseudo-colour contours of the removed tissues from SCANd showing the tissues removed by $\mathrm{HE}$ had higher LAC values than that by CS.

sample data was split into two separate datasets, each consisting of one hemisected tooth only. The in-house 'alignment and subtraction' program was used to generate a data set (SCANd) by subtracting the data set of SCAN2 from SCAN1 after correcting for the spatial shift. From this dataset, subtracted XMT images (fig. 2) and corrected subtraction volume histograms of tissue removed were generated (fig. 3). It can be observed from both figures that HE removed tissues with higher LACs than CS, and that for CS, no tissues having LACs higher than $1.1 \mathrm{~cm}^{-1}$ were removed, whereas for HE, tissues with LACs up to $1.5 \mathrm{~cm}^{-1}$ were excavated. In order to further adjust for residual misalignment artefacts, the cut-off point where no more tissue was removed was set when the number of voxels in the histogram fell below 100 for all the 21 pairs of specimens. It was found that the mean cutoff LACs for HE and CS were $1.27 \pm 0.14$ and $1.09 \pm 0.17$ $\mathrm{cm}^{-1}$, respectively.

To determine the lower threshold of LAC for sound dentine, the method by Willmott et al. [2007] was adopt- 


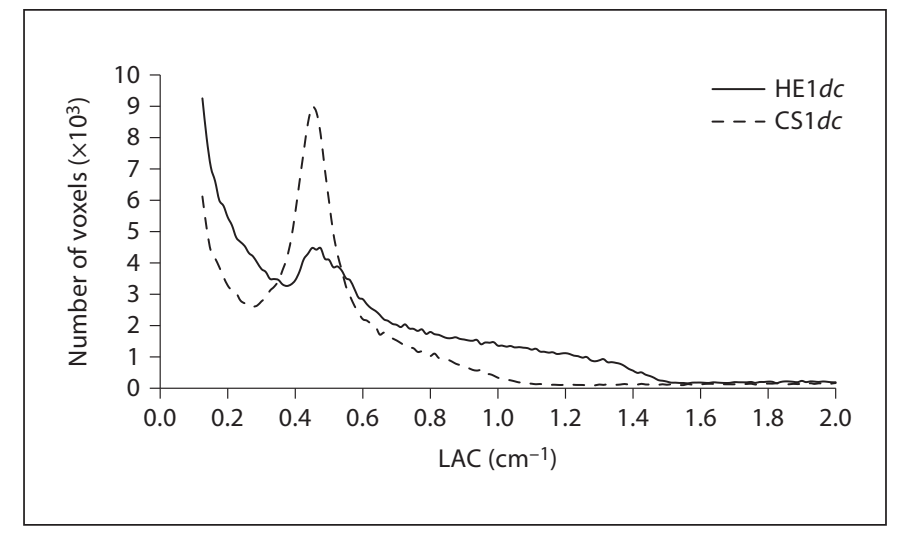

Fig. 3. Corrected subtraction histogram of tissue removed by HE $(\mathrm{HE} 1 d c)$ and chemo-mechanical techniques $(\mathrm{CS} 1 d c)$ from SCAN $d$.

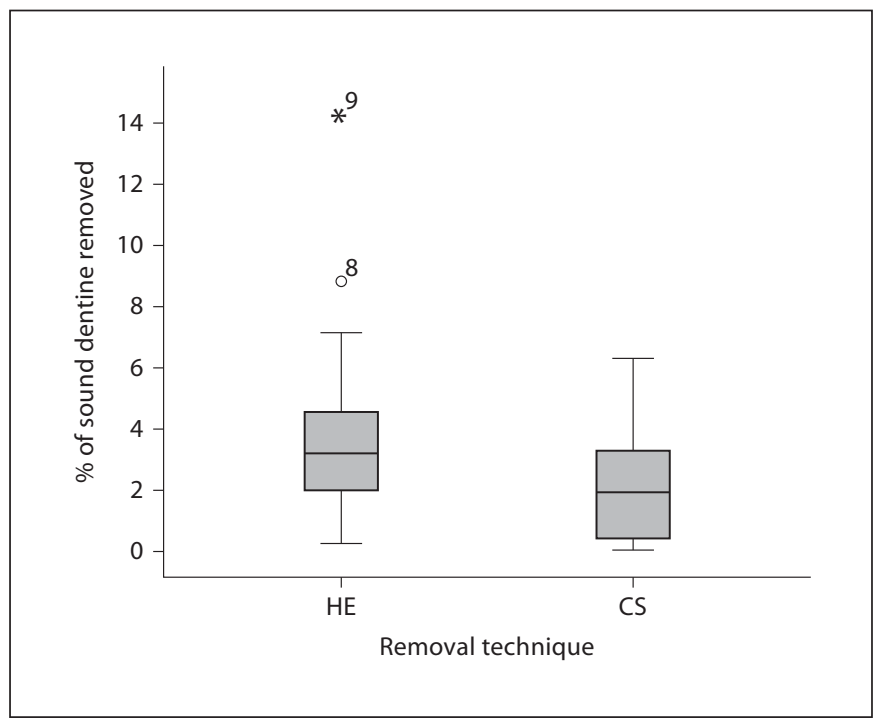

Fig. 4. Comparison of amount of sound dentine removed by HE and CS techniques.

ed in which a histogram of sound dentine from a XMT scan of a caries-free primary molar was obtained. However, instead of using a fixed LAC value at the lower flexion point of the histogram for the lowest threshold for sound dentine, a ratio was calculated by dividing the LAC value at the sound dentine peak by that at the lower flexion end of the histogram. This ratio was then applied to the LAC value at the sound dentine peak for each hemisection to give a corresponding lowest LAC threshold for sound dentine. In the subtraction histogram from
SCANd, the volume of removed sound dentine was calculated by summing all the voxels from this threshold LAC to LAC of $2.0 \mathrm{~cm}^{-1}$ (to exclude any enamel removed during excavation). This volume was then expressed as a percentage of the total volume of all the tissues removed excluding the contribution of water which had a LAC lower than $0.25 \mathrm{~cm}^{-1}$. The results are summarised in figure 4 showing that the CS method removed less sound dentine than HE (mean \pm SD \% of sound dentine: $2.1 \pm$ 1.76 and $4.0 \pm 3.14$, respectively). A paired student $t$ test comparing both techniques showed that the difference of sound dentine removed was significant at $\mathrm{p}=0.011$.

In order to investigate whether the amount of sound dentine removed was dependent on the volume of the carious lesion, a scatter plot diagram was drawn (fig. 5). It was found that for the HE technique, there was a positive relationship between the amount of sound dentine removed and the total volume of the tissue removed. However, this trend was not obvious for the CS technique.

\section{D Analysis}

In order to investigate the boundary region between carious and sound dentine, line profiles, measuring LAC along them, were drawn through the centre of the carious lesion, normal to the tangent at the lowest part of the bowl shaped lesion (fig. 6). Typical features observed were: (1) There was a gentle decline of LACs from sound dentine towards the enamel-dentine junction; (2) after caries removal (HE1 $r$ and CS1 $r$ ), the decline had an abrupt drop indicating the region to which tissue was removed; (3) the LAC of the tissue to which the HE technique removed (HE1r) was in general in the sound dentine region and was higher than that of the CS technique (CS1r).

From this $2 \mathrm{D}$ analysis, the mean ( $\pm \mathrm{SD}$ ) LACs of the tissues to which HE and CS excavated to were $1.42 \pm 0.14$ and $1.15 \pm 0.26 \mathrm{~cm}^{-1}$, respectively.

\section{Mineral Concentration}

To convert LAC values to mineral concentration, the following equation [Willmott et al., 2007] was used, assuming the mineral phase of dentine to be pure hydroxyapatite, $\mathrm{Ca}_{10}\left(\mathrm{PO}_{4}\right)_{6}(\mathrm{OH})_{2}$, with a density of $3.15 \mathrm{~g} \cdot \mathrm{cm}^{-3}$, and the organic phase to be collagen with mass fractions of $53,7,1,17$ and $22 \%$ for carbon, hydrogen, sulphur, oxygen and nitrogen, respectively:

$$
C_{D}=\frac{\mu_{D}-\left(\mu_{\text {mcol }} C_{c o l}\right)}{\mu_{\text {mhap }}}
$$

where: $C_{D}=$ the mineral concentration of dentine or caries; $\mu_{D}=$ the LAC of the dentine or caries $\left(\mathrm{cm}^{-1}\right)$; 
Fig. 5. Scatter plot to show the relationship between the volume of the carious lesion and the amount of sound dentine removed by $\mathrm{HE}$ and CS techniques.

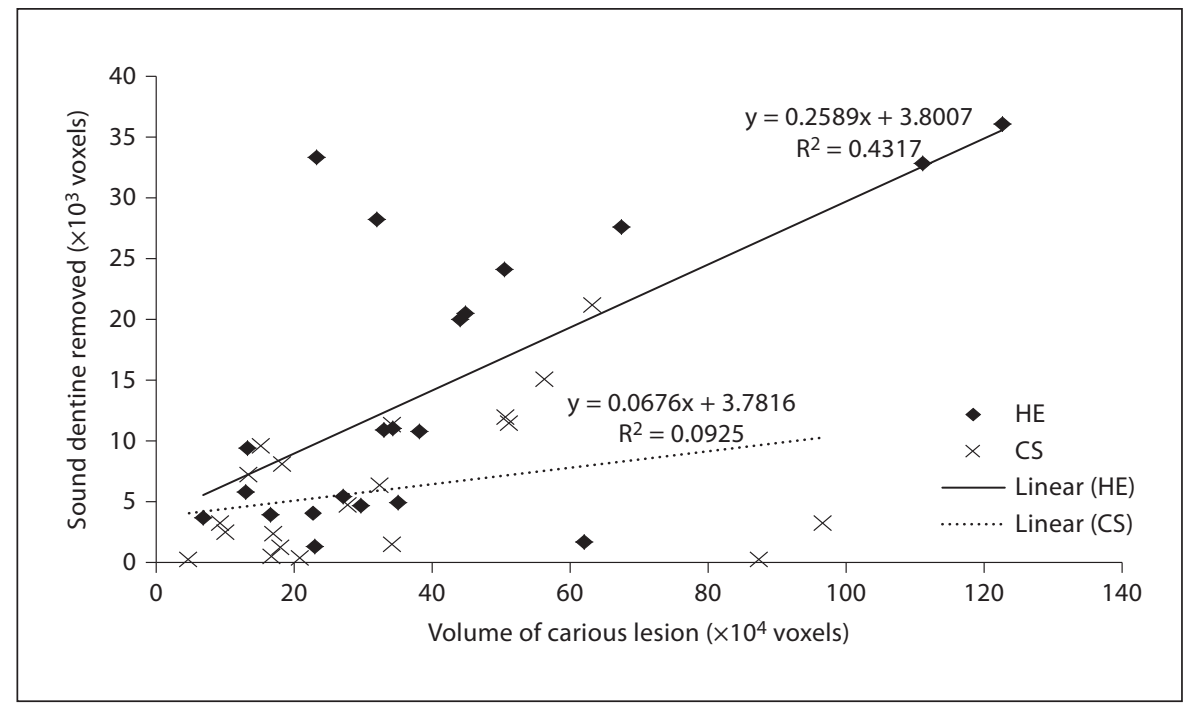

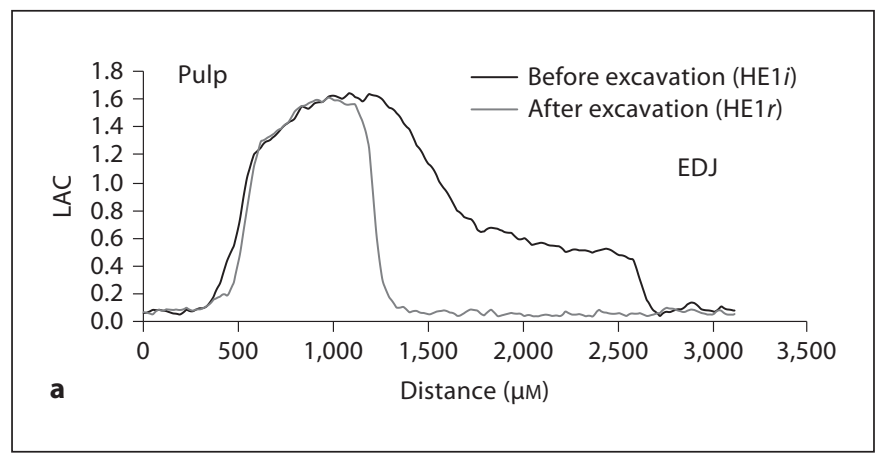

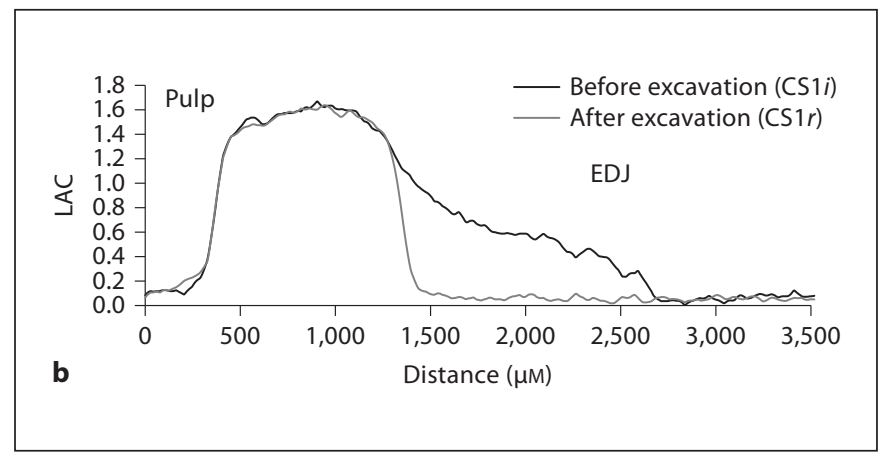

Fig. 6. a Typical line probe through the carious lesion before and after excavation by HE. b Typical line probe through the carious lesion before and after excavation by CS. EDJ = Enamel-dentine junction.

$\mu_{m c o l}=$ the mass attenuation coefficient of collagen $(0.24$ $\mathrm{cm}^{2} \cdot \mathrm{g}^{-1}$ at $\left.40 \mathrm{keV}\right) ; C_{c o l}=$ the concentration of collagen in dentine $\left(0.54 \mathrm{~g} \cdot \mathrm{cm}^{-3}\right) ; \mu_{\text {mhap }}=$ the mass attenuation coefficient of HAP $\left(0.99 \mathrm{~cm}^{2} \cdot \mathrm{g}^{-1}\right.$ at $\left.40 \mathrm{keV}\right)$.

As seen in the histograms in the $3 \mathrm{D}$ analysis, the distribution is not Gaussian for each type of tissue. Hence the modal value, instead of the mean, was used to be the representative value for the tissue. For the pool samples, the mean modal mineral concentration for sound dentine was determined to be $1.44 \pm 0.09 \mathrm{~g} \cdot \mathrm{cm}^{-3}$. However, due to proteolysis in caries progression, the $C_{c o l}$ could be zero in the caries region [Willmott et al., 2007]. Hence, the mean modal mineral concentration for the main body of the lesion was determined to be $0.30 \pm 0.01$ $\mathrm{g} \cdot \mathrm{cm}^{-3}$ when all the collagen was assumed to be present; and $0.43 \pm 0.12 \mathrm{~g} \cdot \mathrm{cm}^{-3}$ when all collagen was assumed to be proteolysed, and the collagen concentration was zero.

\section{Discussion}

New scientific developments in cariology, dental materials and diagnostic systems have shifted dentistry's approach towards minimal intervention [Burke, 2003]. One golden aim for clinicians is to remove the infected layer of dentine, leaving the affected layer to preserve the integrity of the tooth. However, even with high-resolution light microscopy, the boundary between these two layers is not well defined. Banerjee et al. [2002] showed that bac- 
terial infiltration could be detected even in the tubules of sound dentine. Therefore, it may not be possible to locate the bacteria-free demineralised dentine region according to the original definition of affected dentine. Nevertheless, there is a consensus that the soft superficial carious layer should be removed, leaving a harder, partially demineralised 'recalcifiable' layer behind [Ogawa et al., 1983; Kidd, 2004]. As this tactile determination is subjective, a chemo-mechanical system has been developed to aid clinicians preserving this recalcifiable layer [Banerjee et al., 2000; Celiberti el al., 2006]. However, even with the chemical aid, variability would still exist among operators. Hence, a single operator was used in the present study to avoid the inter-operator difference, assuming that this operator, who is an experienced clinician, was consistent in his approach to caries removal of all the lesions.

Instead of using conventional microscopic techniques to investigate the effectiveness of caries removal technique in $2 \mathrm{D}$, the present study used a novel XMT scanner to compare the efficacies of two techniques in 3D. The main advantages of this scanner over commercially available laboratory scanners are its higher signal to noise ratio and lack of ring artefacts [Davis and Elliott, 2003] so that quantitative measurements can be made and subtle changes in mineral concentrations can be detected. These subtle changes cannot be quantified or easily detected by the conventional 'gold' standard of optical light microscopy which depends on light transmission through thin sections. Even with polarising light microscopy, the measurements are only semi-quantitative because of its dependence on pore sizes and imbibing media. Quantitative backscattered electron microscopy, using aromatic dimethacrylate as calibrating standard, can quantify mineral concentration of calcified tissues in high resolution [Boyde et al., 1995]. However, like other microscopic techniques, it is $2 \mathrm{D}$ and destructive; therefore, changes resulting from experimental challenge in the same tissue cannot be followed through. Hence, the ideal 3D, non-destructive and quantitative technique in measuring small mineral changes is probably XMT using a synchrotron source because of its ability to produce monochromatic radiation [Kinney et al., 1994, 1995] which avoids polychromatic artefacts, thus accurate LACs can be obtained. Since synchrotron beam time is not readily available, an XMT system using a laboratory source with polychromatic correction was used in this study to validate the efficacies of the two caries removal techniques.
The results showed that the volume of sound dentine removed by CS technique was half of that by $\mathrm{HE}$, and was much less dependent, if at all, on the volume of total caries lesion than HE. Hence, the present study confirms that CS is the more conservative technique in preserving sound tissue, as found in previous studies [Banerjee et al., 2000; Morrow et al., 2000; Lozano-Chourio et al., 2006]. However, concern has been raised with regard to the residual layer of partially demineralised dentine, also shown by Hahn et al. [2004]. This layer has been regarded by some authors to be caries active because it has a $\mathrm{pH}<5$ [Splieth et al., 2001]. Nevertheless, this layer could be regarded as dentine corresponding to the translucent zone [Arnold et al., 2003], with unaffected collagen, since CS only removes denatured collagen [Hannig, 1999]. Hence, this layer should be preserved as it may have the potential to remineralise. From the $3 \mathrm{D}$ analysis, this residual layer had a mean LAC $>1.09 \mathrm{~cm}^{-1}$, corresponding to a mineral concentration of $0.97 \mathrm{~g} \cdot \mathrm{cm}^{-3}$ and a mineral volume $\%$ of 30.8 . This value is similar to that found by Clementino-Luedemann et al. [2006] in their micro-CT study. Using the exponential relationship between mineral volume $\%(\mathrm{vm})$ and hardness $(H)$ where $H=0.005 e^{0.126 \mathrm{vm}}$ [Angker et al., 2004], a Knoop hardness number value of $24.7 \mathrm{~kg} \cdot \mathrm{mm}^{-2}$ was obtained. From the $2 \mathrm{D}$ analysis, the corresponding threshold hardness was $31.6 \mathrm{~kg} \cdot \mathrm{mm}^{-2}$. These values are between the hardness values for carious and sound dentine [Paolinelis et al., 2006], therefore, $25 \mathrm{~kg} \cdot \mathrm{mm}^{-2}$ could be used as the threshold hardness above which dentine should be preserved. This threshold may not mark the exact boundary between infected and affected dentines because XMT measures mineral concentration rather than bacteria infiltration. However, as bacteria can be detected in sound dentine [Banerjee et al., 2002], it may not be possible to locate bacteria-free demineralised dentine according to the strict definition of affected dentine.

In conclusion, XMT is shown to be a valuable tool in measuring subtle changes in mineral concentration. Using this technique, the CS chemo-mechanical technique was validated to be more conservative than $\mathrm{HE}$, preserving dentine with a mineral concentration $>0.97 \mathrm{~g} \cdot \mathrm{cm}^{-3}$ (67\% of that for sound dentine), with an equivalent Knoop hardness number of $25 \mathrm{~kg} \cdot \mathrm{mm}^{-2}$. Further studies are required involving more operators to confirm this as the ideal threshold and to ascertain to what extent this excavation limit is determined by the softening effect of the CS solution or by the self-limiting action of the associated hand instrument. 


\section{Acknowledgement}

The authors thank the MRC (Grant Ref.: G122/12) for supporting this project.

\section{Disclosure Statement}

The authors have no conflicts of interest to disclose.

\section{References}

-Angker L, Nockolds C, Swain MV, Kilpatrick N: Correlating the mechanical properties to the mineral content of carious dentine - a comparative study using an ultra-micro indentation system (UMIS) and SEM-BSE signals. Arch Oral Biol 2004;49:369-378.

-Arnold WH, Konopka S, Kriwalsky MS, Gaengler P: Morphological analysis and chemical content of natural dentin carious lesion zones. Ann Anat 2003;185:419-424.

Banerjee A, Kidd EA, Watson TF: In vitro evaluation of five alternative methods of carious dentine excavation. Caries Res 2000;34:144150.

Banerjee A, Yasseri M, Munson M: A method for the detection and quantification of bacteria in human carious dentine using fluorescent in situ hybridisation. J Dent 2002;30:359363.

Boston DW: New device for selective dentin caries removal. Quintessence Int 2003;34:678685.

Boyde A, Davy K, Jones, SJ: Standards for mineral quantitation of human bone by analysis of backscattered electron images. Scanning 1995; 17:6-7.

Burke FJ: From extension for prevention to prevention of extension: (minimal intervention dentistry). Dental Update 2003;30:492-502.

-Celiberti P, Francescut P, Lussi A: Performance of four dentine excavation methods in deciduous teeth. Caries Res 2006;40:117-123.

-Clementino-Luedemann TN, Dabanoglu A, Ilie N, Hickel R, Kunzelmann KH: Micro-computed tomographic evaluation of a new enzyme solution for caries removal in deciduous teeth. Dent Mater J 2006;25:675-683.
Davis GR, Elliott JC: High definition X-ray microtomography using a conventional impact X-ray source. J Phys IV France 2003;104:131134.

Fluckiger L, Waltimo T, Stich H, Lussi A: Comparison of chemomechanical caries removal using Carisolv or conventional hand excavation in deciduous teeth in vitro. J Dent 2005; 33:87-90.

Fusayama T, Okuse K, Hosoda H: Relationship between hardness, discoloration, and microbial invasion in carious dentin. J Dent Res 1966;45:1033-1046.

-Hahn SK, Kim JW, Lee SH, Kim CC, Hahn SH, Jang KT: Microcomputed tomographic assessment of chemomechanical caries removal. Caries Res 2004;38:75-78.

Hannig M: Effect of Carisolv solution on sound, demineralized and denatured dentin - an ultrastructural investigation. Clin Oral Investig 1999;3:155-159.

Hubbell JH, Seltzer SM: Tables of X-ray mass attenuation coefficients and mass energy-absorption coefficients from $1 \mathrm{KeV}$ to $20 \mathrm{MeV}$ for elements $Z=1$ to 92 and 48 additional substances of dosimetric interest. Gaithersburg, National Institute of Standards and Technology, NISTIR 5632, 1995.

Kidd EA: How 'clean' must a cavity be before restoration? Caries Res 2004;38:305-313.

Kidd EA: Essentials of dental caries. New York, Oxford University Press, 2005.

Kinney JH, Balooch M, Haupt DL Jr., Marshall SJ, Marshall GW Jr.: Mineral distribution and dimensional changes in human dentin during demineralization. J Dent Res 1995;74: 1179-1184.

Kinney JH, Marshall GW Jr., Marshall SJ: Threedimensional mapping of mineral densities in carious dentin: Theory and method. Scanning Microsc 1994;8:197-204.
Lozano-Chourio MA, Zambrano O, Gonzalez $\mathrm{H}$, Quero M: Clinical randomized controlled trial of chemomechanical caries removal (Carisolv $^{\mathrm{TM}}$ ). Int J Paediatr Dent 2006;16: 161-167.

Lula EC, Monteiro-Neto V, Alves CM, Ribeiro CC: Microbiological analysis after complete or partial removal of carious dentin in primary teeth: a randomized clinical trial. Caries Res 2009;43:354-358.

- Morrow LA, Hassall DC, Watts DC, Wilson NH: A chemomechanical method for caries removal. Dent Update 2000;27:398-401.

- Ogawa K, Yamashita Y, Ichijo T, Fusayama T: The ultrastructure and hardness of the transparent layer of human carious dentin. J Dent Res 1983;62:7-10.

- Paolinelis G, Watson TF, Banerjee A: Microhardness as a predictor of sound and carious dentine removal using alumina air abrasion. Caries Res 2006;40:292-295.

-Rafique S, Fiske J, Banerjee A: Clinical trial of an air-abrasion/chemomechanical operative procedure for the restorative treatment of dental patients. Caries Res 2003;37:360-364.

- Splieth C, Rosin M, Gellissen B: Determination of residual dentine caries after conventional mechanical and chemomechanical caries removal with Carisolv. Clin Oral Investig 2001; 5:250-253.

Willmott NS, Wong FS, Davis GR: An X-ray microtomography study on the mineral concentration of carious dentine removed during cavity preparation in deciduous molars. Caries Res 2007;41:129-134. 